\title{
Concluding Commentary
}

\section{Consumer-Directed Health Care: Will It Improve Health System Performance?}

Karen Davis

The excellent set of papers contained in this issue provides important insight into early experience with consumer-directed health care plans. While more experience and research are required to reach definitive conclusions, the evidence to date raises major cautions about relying on a consumer-directed health care movement to address fundamental problems in the health care system. Longer-term solutions aimed directly at the root causes of higher costs are needed to improve health system performance and to achieve better quality, safety, and efficiency of care provision.

\section{THE THEORY UNDERLYING CONSUMER-DIRECTED HEALTH CARE}

The consumer-directed health care strategy is predicated on the notion that health care services are overutilized, and that giving financial incentives to patients will reduce use of services of marginal or no value. It also will give patients an incentive to seek out lower-cost providers of care. While there is certainly evidence of overutilization of some services, underutilization appears to be a far greater problem (McGlynn et al. 2003). Even clear instances of overutilization are often the result of provider decisions and may not be responsive to consumer incentives. About one-fifth of sicker patients report receiving duplicate tests from different physicians, and medical records and tests not being readily available when needed (Blendon et al. 2003).

While there are different versions of "consumer-driven health care," most interest has centered on combining a high-deductible health insurance plan (e.g., \$1,500) with a health reimbursement account (HRA) to cover part of the out-of-pocket cost of health care expenses (e.g., \$500). The unused balance in the HRA can be carried over into future years, but employees forfeit the balance if they leave the employer. Typically, consumer-driven health care plans are an additional option for employees; a few employers, however, use it as a "replacement product" and offer only the high-deductible plan coupled with an HRA. Other forms of consumer-directed health plans 
include "tiered point of care" with variable cost sharing for hospital or physician services based on the cost or cost and quality of provider selected, and "tiered premium" strategies that let consumers pick their own package of benefits and networks of providers, with varying employee premiums based on comprehensiveness of benefits and costliness or cost and quality of providers (Rosenthal 2004; Gabel, Lo Sasso, and Rice 2002).

There is very little debate that if patients pay more health care bills directly out-of-pocket that they will consume less care. It is deeply rooted in economic theory and empirical studies finding that the quantity of health care services demanded varies inversely with price. A quantity of a service that is relatively "price elastic" (e.g., discretionary care such as plastic surgery) will vary markedly with price while the quantity of a service that is relatively "price inelastic" (e.g., trauma care for accident victims) will vary little with price. Insurance has the effect of reducing the "net price" paid by the consumer, resulting in higher utilization than would otherwise be the case. Increases in utilization as a result of insurance coverage are greater for those services that are "price elastic." Or conversely, increasing patient cost sharing can be expected to increase the "net price," reduce utilization especially of discretionary services, and lower total health spending, as well as the cost of insurance (both because a lower percent of the bill is covered and because utilization declines).

The major empirical test of the effect of cost sharing was the RAND Health Insurance Experiment (HIE). The HIE in 1973 randomly assigned 7,706 individuals in six geographic markets to health insurance plans with varying cost sharing: free care for all services, and plans with differing coinsurance ( 25 percent, 50 percent, 95 percent), all subject to a total ceiling on out-of-pocket costs of $\$ 1,000$ ( $\$ 4,150$ in 2003 dollars) or a ceiling based on income if lower $(5,10$, or 15 percent of income). Its primary conclusion confirmed the economic theory that when consumers face higher cost sharing they will consume fewer services (Newhouse 1981).

The RAND experiment excluded persons aged 62 and older and those who were permanently and totally disabled at the time of the demonstration. Its results, therefore, are particularly fitting for employer-based coverage. Further, to avoid making anyone participating in the plan worse off, everyone given a cost-sharing plan was also given a lump sum payment of the maximum out-of-pocket costs $(\$ 1,000)$ less the maximum out-of-pocket under their

Address correspondence to Karen Davis, Ph.D., The Commonwealth Fund, One East 75th Street, New York, NY 10021 
current coverage. In some ways, therefore, it was an early forerunner of consumer-directed health plans that combine a high deductible with a health reimbursement account-although in the RAND HIE consumers could use the lump sum payment for any purpose, not just health care.

The HIE found that use of physician services was more sensitive to cost sharing than use of hospital services. Total spending was 60 percent higher for patients in "free care" plans than for patients with cost sharing. Patients with cost sharing had one-third fewer visits to a physician and were hospitalized about one-third less often. While the RAND results were not particularly surprising to economists, they disproved the argument that cost sharing, by reducing preventive and early primary care, would lead to higher hospitalization and higher costs in the long term. These results, however, are qualified in that the sample excluded aged and disabled individuals, and set an income-related ceiling on out-of-pocket payments such as 5, 10, or 15 percent. Higher out-of-pocket costs or inclusion of sicker patients may have led to different effects.

What is perhaps less well known about the HIE is its effects on health status and use of clinically appropriate or inappropriate services. Is it only "discretionary" or "nonessential" health utilization that is affected by cost sharing? Sometimes the HIE has been characterized as finding no adverse effect on health status, but a closer reading of the results shows that there were adverse effects on health for lower-income and high-risk individuals (Rassell 1995). For example, for low-income persons with high blood pressure, free care brought better control of blood pressure (Brook et al. 1983). Free care reduced the risk of early death among those at high risk. Coverage of services such as vision care also made a difference; free care individuals with poor vision were more likely to have vision correction.

Lohr (1986) found that cost sharing in the HIE reduced the likelihood of receiving effective medical care. These effects were particularly marked for low-income children and adults. For example, the probability that low-income children in cost-sharing plans received effective medical services for acute conditions was 56 percent of that of low-income children in plans with no cost sharing; the rate for low-income adults was 59 percent. Even for higherincome children and adults, those with cost sharing had a lower probability of receiving effective services than those in "free care" plans (85 percent for higher-income children and 71 percent for higher-income adults compared to higher-income children and adults with no cost sharing). Lurie et al. (1987) found that cost sharing in the HIE reduced use of preventive services. For example, among women 45 to 65 years of age, cost sharing reduced the use of 
Pap smears from 65 percent to 52 percent over a three-year period. Siu et al. (1986) also found that cost sharing reduced appropriate hospital admissions by 22 percent, and reduced inappropriate hospital admissions by 27 percentusing blinded clinician ratings of hospital admission records to determine appropriateness. Thus, cost sharing was not a sensitive technique for discriminating between appropriate and inappropriate use of hospital services.

Over the years a number of studies have confirmed the RAND findings. Lurie et al. (1984) found that low-income individuals suffered adverse health effects when they lost Medi-Cal insurance coverage. Tamblyn et al. (2001) found that prescription drug cost sharing in Canada led to both a reduction in use of essential drugs (15 percent for elderly and 22 percent for low-income individuals) and an increase in adverse events (117 percent increase for elderly and 97 percent for low-income). Moving to three tiers and increased cost sharing for prescription drugs by one employer in the United States led to failure to fill needed prescriptions such as ACE inhibitors (16 percent discontinued compared to 6 percent in control group) and statins (21 percent discontinued compared to 11 percent in control group) (Huskamp et al. 2003). The Medical Outcomes Study followed 3,589 chronically ill patients for four years and concluded that cost sharing reduced the use of care for both minor and serious symptoms, although no differences in self-reported health status were observed (Wong et al. 2001).

These studies suggest the importance of looking beyond whether consumer-directed health care leads to a reduction in utilization or total spending on health care services-to examining whether the reduction in utilization is appropriate or inappropriate and whether there are adverse health consequences. It should not be surprising based on the empirical evidence over the past three decades as well as more recent studies that increased cost sharing will lead to reduced use, lower total health spending, and slower increases in insurance premiums or expenses covered by insurance. What matters is whether it discourages patients from getting effective or appropriate services, or simply reduces use of services that are inappropriate or overused, but have no effect on health outcomes.

There are even greater concerns for the effect of financial incentives on lower-income populations and those with serious illnesses. The RAND HIE set lower ceilings for lower-income individuals, for example, plans limited cost sharing to 5,10 , or 15 percent of income. Most employer plans do not include reduced cost sharing for lower-wage workers. Recent studies of cost sharing underscore this concern. Studies of prescription drug utilization that imposed 
Figure 1: Health Care Costs Concentrated in Sick Few

Distribution of Health Expenditures for the U. S. Population, by Magnitude of Expenditure, 1997

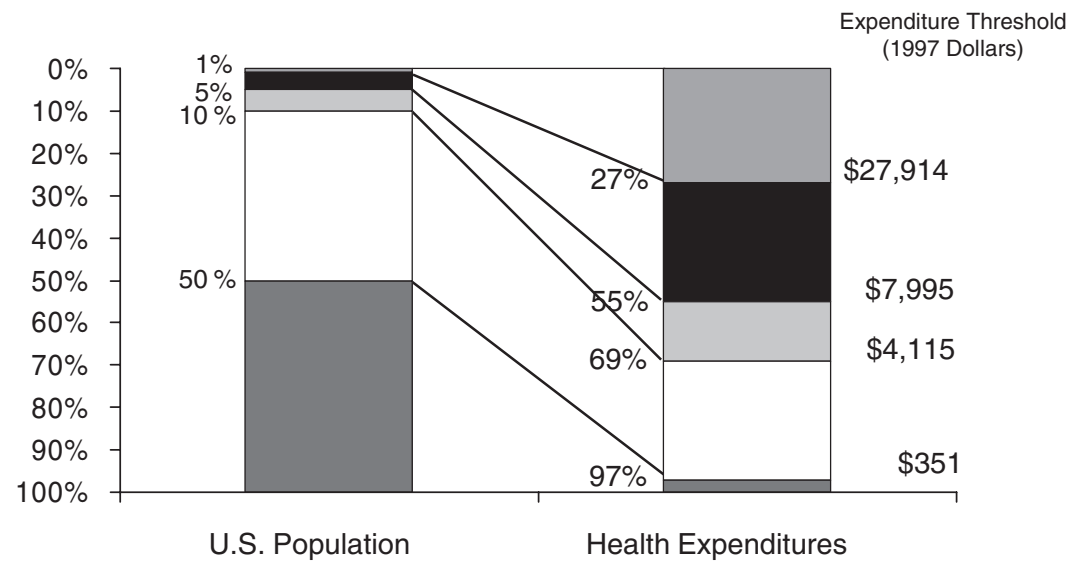

Source: Monheit 2003.

copayments or set limits on covered drugs by low-income patients indicate quite high sensitivity that can lead to reduced use of essential medicines and increased use of hospital and emergency department care, and increased institutionalization in nursing homes (Soumerai et al. 1994, 1987, 1991). Similarly Stuart and Zacker (1999) found that in states that imposed copayments on Medicaid beneficiaries, the likelihood of filling prescriptions was reduced, and the burden fell disproportionately on those in poor health.

In assessing the value of consumer-directed health plans it is particularly important to bear in mind that 10 percent of individuals account for 69 percent of health care costs (see Figure 1) (Monheit 2003). Furthermore, high cost tends to persist over time, subjecting the same individuals to continuing high costs. Such individuals would quickly exhaust a health reimbursement account and be subjected to sustained, high out-of-pocket costs. At the other end of the spectrum, Monheit finds that 50 percent of individuals account for only three percent of health care outlays, all with expenditures under \$350 in 1997. Giving such individuals a $\$ 500$ or $\$ 1,000$ health reimbursement account will increase costs to employers-since such individuals would not have used that level of services. This could lead employers to reduce the health reimbursement account amount or eliminate it completely over time. 


\section{EARLY EXPERIENCE WITH CONSUMER-DIRECTED HEALTH CARE}

The papers in this issue lend preliminary support to four main conclusions about consumer-directed health care:

- Enrollment is relatively limited when offered as an option.

- Healthier and higher-income individuals are more likely to enroll.

- Enrollees tend to reduce utilization and health care expenses, although evidence is skimpiest on this point.

- Most enrollees are relatively satisfied with the choice and reenrollment rates are high.

\section{EnRollment in CONSUMER-DiReCted HeAlth Plans (CDHP)}

Rosenthal (2004) estimates that consumer-directed health plans are still in their infancy, and constitute a relatively small part of the employer health insurance market. Only about 270,000 individuals are in an HRA, out of over 160 million people covered by employer plans. Point-of-care tiered plans enrolled an estimated 1.7 million beneficiaries, and 500,000 people were enrolled in premium-tiered plans in 2003.

Enrollment in firms offering HRAs as a choice is also relatively lowusually less than 10 percent of those offered a high-deductible CDHP product along with other insurance plans enroll. Tollen, Ross, and Poor (2004) found that a total of six percent of Humana employees enrolled in two consumer-directed health plan options; other employees picked the HMO or one of the two PPO options. In their four employer case studies Lo Sasso et al. (2004) found that enrollment ranged from 4 percent to 25 percent of employees, with enrollment typically increasing in the second year offered.

\section{FAVORABLE RisK SELECTION BY CONSUMER-DiRECTED HEALTH PLANS}

The primary concern is that CDHP will primarily attract healthier and higherincome individuals, leaving sicker and lower-wage employees in higher-cost 
alternatives (McNeill 2004). Studies tend to measure health status either by demographics - such as age, gender, or family size-or by utilization of services prior to enrollment. Tollen, Ross, and Poor (2004) find no evidence of favorable risk selection based on demographic data, but better measures of risk based on prior use and health expenditures indicate risk segmentation took place. For each of five health care services, prior year usage was 60 percent of the average for all enrollees. Tollen, Ross, and Poor also found that those selecting the CDHP options had slightly higher salaries.

These findings were confirmed by Lo Sasso and colleagues' (2004) case studies of four employers. In one case, employees with higher salaries were more likely to enroll in the Definity CDHP product (6.4 percent versus 3.7 percent). In the case of another employer, prior-year enrollment claims expenses for those who enrolled in the CDHP product were 50 percent of the overall level for all employees.

Fowles and colleagues' (2004) survey of Humana employees found that 7 percent of employees selected one of the two CDHP options. They were less likely to be African American, less likely to have a chronic health problem, and more likely to have had no recent physician visits.

Parente, Feldman, and Christianson (2004b) also found that higherincome employees were more likely to enroll in a CDHP option with the CDHP having less than half their share of lower-income employees. Initially the CDHP had the lowest average calculated illness burden case-mix index, but their favorable selection did not continue over time. Hospitalization rates of the CDHP rose markedly by the third year, as did the overall case-mix index. These results were confounded, however, because a major medical center only participated in the CDHP plan, and was an "out-of-network" provider in the HMO and PPO options; the authors suggest that those individuals desiring care at the medical center may have opted for CDHP coverage to have access to the medical center.

Christianson, Parente, and Feldman (2004) also found that University of Minnesota faculty, academic professionals, and administrators were more likely to select the CDHP than other employees; those covered by a civil service bargaining unit were less likely to enroll in the CDHP. Parente, Feldman, and Christianson (2004a) confirmed that higher income employees at the University of Minnesota were more likely to choose the CDHP, but they found no differences by chronic illness of the employee or family members on choice of plan. Employees with a chronic health condition themselves or in their family were more price-sensitive, and more likely to choose plans with lower out-of-pocket premiums. 


\section{EFFECT ON UTILIZATION OF SERVICES}

Tollen, Ross, and Poor (2004) found that more than 85 percent of CDHC enrollees spent less than $\$ 1,000$ on health care, compared with two-thirds of enrollees in the HMO and PPO options. Most of this difference, however, they attributed to better health status, rather than price sensitivity. Humana did not permit employees to carry over their HRA balance, or to apply the allowance toward noncovered services. It is not clear that as an employer that Humana "saved" money, given its combined outlays for the insurance product and the HRA allowance.

Lo Sasso et al. (2004) similarly did not have evidence on change in utilization as a result of enrollment. Although they also found that less than half of enrollees used their HRA allowance of $\$ 1,000$, and expenditures were less than half that of PPO enrollees, they suspected that this was attributable to the favorable risk selection rather than the effect of the financial incentives.

Parente, Feldman, and Christianson (2004b) analyzed the CDHP experience of one large employer over a three-year period. Initially the CDHP had lower spending, lower prescription drug use, and fewer physician visits, which may have been related to "nurse line coaching services" or comparative information on pharmaceutical prices. However, hospital admissions for CDHP enrollees doubled by the third year from when first introduced, eliminating any cost advantage for the employer by the third year. While the jump in hospitalization might have been caused by "underuse" of physician services to control conditions at an early stage, it may also be an anomaly based on the fact that a major medical center only participated in the CDHP, and was only available to HMO and PPO enrollees with substantial out-of-pocket, out-of-network cost sharing.

\section{SATISFACTION WITH CDHP}

Reenrollment in CDHP products is relatively high, usually on the order of 90 percent, and a similarly high proportion of enrollees report satisfaction (Lo Sasso et al. 2004). This suggests that those who choose such plans because they believe they are a "better deal" for them continue to do so. It is interesting, however, that while voting with their feet to continue in the plan only a relatively small percentage-30 percent-would unqualifiedly recommend them to others (Christianson, Parente, and Feldman 2004). This may suggest that they perceive their own circumstances to be relatively unique, and may 
not make the plan the best choice for others. Interestingly, however, some walk away from the plan after one year, even though by doing so they lose balances that could have been carried forward.

Christianson et al. (2004) found that University of Minnesota employees enrolled in the CDHP were significantly less likely to rate their plan well, but the differences were small (CAHPS score of 7.46 versus 7.55). Forty-six percent of CDHP enrollees reported they had a particularly positive experience with the plan, while 24 percent said they had a particularly negative experience. However, only 8 percent switched from the CDHP to another plan at the end of the contract year. Thirty percent said they would definitely recommend the plan, while another 57 percent said they would recommend it depending on the situation.

There is also some indication in the studies that few people find the CDHP easy to understand or the Internet-based tools easy to use. Those professionals who are more apt to use the Internet in their professional or personal life, or who routinely make financial and risk decisions are more attracted to the plans.

\section{IMPLICATIONS}

These studies are too preliminary and the consumer-directed health plan products too new to reach firm conclusions about their long-term value. However, concerns are raised by the initial experience. It seems clear that they are relatively more attractive to higher-income individuals. When health status is measured by prior utilization-rather than demographic characteristics such as age or presence of chronic conditions-CDHP plans appear to experience favorable risk selection. The downside of the growth of CDHP is likely to be increasing market segmentation, with lower-income and sicker individuals served by managed care plans and higher-income, healthier individuals enrolled in CDHP products. Without risk adjustment, sicker and lower-income individuals will pay higher premiums, and HMOs may eventually face a "death spiral" as unfavorable risk selection worsens.

The studies provide almost no evidence about the effect on use of appropriate or inappropriate care. Rosenthal and Milstein (2004) report that few CDHP plans advise patients who are underusing services. Some plans do exclude preventive services from the deductible, but financial incentives to avoid seeking care even in the face of serious symptoms could contribute to underutilization of essential services-as other cost-sharing studies have 
found. Nor is anything known about the financial burden on lower-wage employees with greater out-of-pocket costs not covered by health reimbursement accounts.

The studies do suggest that CDHP products have high information requirements in order for enrollees to understand the plans and use them effectively. Quality and even cost information are often not available (Rosenthal and Milstein 2004).

\section{IS THERE A BETTER AlteRnATIVE?}

Employers offer health insurance to their employees for a variety of reasons, including attracting and retaining high quality employees, improving employee morale, and enhancing employee productivity. To the extent that employers effectively reduce benefits and increase employee out-of-pocket costs, or pressure employees to enroll in plan options that don't work for them, these advantages of employee health benefits will be undermined.

Further, by fostering favorable selection into CDHP products, integrated health care delivery systems with good performance on cost and quality are likely to experience a long-term decline in enrollment as their premiums rise as a result of enrolling "sicker" enrollees (Tollen, Ross, and Poor 2004).

The real goal should be to promote the spread of high-performing health systems, hospitals, and physicians. A number of new studies are finding wide variation in cost over an episode of illness across hospitals and physicians and even wider variation in quality performance (Grossbart 2003; Milstein 2003; Institute for Healthcare Improvement 2003). Yet, few private insurers, managed care plans, or public programs reward hospitals or physicians with superior quality or efficiency (Davis 2004; Maio et al. 2003; Goldfarb et al. 2003). Public information on comprehensive measures of quality at the individual hospital or physician level is extremely limited and rudimentary. Little is known about the "best practices" that lead some providers to achieve high performance, nor are the tools such as electronic medical records, clinical guidelines, patient reminders, and physician decision support systems that might spread their adoption in place.

If we are to achieve a truly high-performance health system, bold action is required. The following steps would start us on this course:

- Public reporting of cost and quality data on physicians, hospitals, nursing homes, other health care providers, and 
health plans. The Centers for Medicare and Medicaid Services has been a leader in posting nursing home quality data on its website, but this is just a modest beginning. The new Medicare prescription drug legislation also spurs reporting by hospitals of a limited set of quality indicators. If we are serious about doing better, we need to know where we stand, routinely collecting comprehensive quality measures across a broad range of providers.

- Investment in health information technology. Other countries are quickly surpassing the United States in the adoption of electronic medical records and electronic prescribing. They are doing so because the government has been willing to invest in the infrastructure and establish the standards required to make this potential a reality.

- Development and promulgation of clinical guidelines and quality standards. It is long past time to simply pay for services rendered without establishing a scientific basis for effectiveness-not just for new drugs, but for consultations, procedures, and tests. This could be accomplished through establishment of a new National Institute on Clinical Excellence and Effectiveness (Schoenbaum, Audet, and Davis 2003).

- Paying for performance. Medicare and private insurers tend not to vary payment rates with quality. They pay for defects, whether those defects are surgeries that need to be repeated; infections that arise from failing to use state-of-the-art technology, such as catheters impregnated with antibiotics for heart valve patients; or medication errors. The Center for Medicare and Medicaid Services has embarked on some modest initiatives to begin testing paying-for-performance rewards. Medicare can and should be a leader in promoting quality. These efforts need to be substantially expanded and best practices documented and disseminated. Medicare's leadership can be instrumental in moving private payers as well; to date, very few private insurers have instituted "value-based purchasing" strategies.

- Investment in research. We urgently need to gather evidence on what works to improve care, eliminate waste and ineffective care, and promote greater efficiency, including use of modern information technology, teamwork, and improved care processes. Any industry that fails to invest in research to improve quality and efficiency is going to be a backward industry. The federal government pays $\$ 455$ 
billion for health care in the United States but devotes only $\$ 300$ million to the budget of the Agency for Healthcare Research and Quality (AHRQ) for learning effective ways to improve the performance of the U.S. health system. The quality report on U.S. health care recently issued by AHRQ is an important starting point (Agency for Healthcare Research and Quality 2003). But it needs to be followed with an investment in research up to the task of ensuring that the United States is a high-performing health system worthy of the twenty-first century.

These strategies go to the root causes of poor performance in the health care system, rather than turning to the blunt instrument of consumer financial incentives. They would speed the adoption of modern information technology, and provide powerful financial incentives to hospitals, physicians, and integrated health care delivery systems to improve quality, safety, and efficiency performance.

Better public information could also be helpful to consumers in choosing providers, and could be used to reward patients for choosing such providers, rather than penalizing those who do not. For example, Medicare and private plans could designate providers in the top quartile on quality and efficiency measures, and provide discounted premiums or cost sharing to beneficiaries choosing such provider networks. PacificCare provides "HealthCredits" good toward the purchase of treadmills or mountain bikes for enrollees who enroll in disease management programs or take other steps to improve their health (Ho 2004).

Consumer-directed health care-if it is primarily a tool for shifting costs from employers to employees-will quickly be discredited. A strategy aimed primarily at providers to identify, demand, and reward high performance, with positive incentives for consumers in a complementary role, is likely to have greater long-term success and acceptability.

\section{REFERENCES}

Agency for Healthcare Research and Quality. 2003. National Healthcare Quality Report. Rockville, MD: Agency for Healthcare Research and Quality.

Blendon, R., C. Schoen, C. DesRoches, R. Osborn, and K. Zapert. 2003. "Common Concerns amid Diverse Systems: Health Care Experiences in Five Countries." Health Affairs 22 (3): 106-21. 
Brook, R., J. E. Ware, W. H. Rogers, E. B. Keeler, A. R. Davies, C. A. Donald, G. A. Goldberg, K. N. Lohr, P. C. Masthay, and J. P. Newhouse. 1983. "Does Free Care Improve Adults' Health? Results from a Randomized Controlled Trial." New England Journal of Medicine 309 (23): 1426-34.

Christianson, J., S. T. Parente, and R. Feldman. 2004. "Consumer Experiences in a Consumer-Driven Health Plan.” Health Services Research 39 (4, part 2): 1123-40.

Davis, K. 2004. Making Health Care Affordable for All Americans. New York: The Commonwealth Fund. Available at http://www.cmwf.org/programs/quality/ davis_senatehelptestimony_714.pdf

Fowles, J., E. A. Kind, B. L. Braun, and J. Bertko. 2004. "Early Experience with Employee Choice of Consumer-Directed Health Plans and Satisfaction with Enrollment." Health Services Research 39 (4, part 2): 1141-58.

Gabel, J. R., A. T. Lo Sasso, and T. Rice. 2002. "Consumer Driven Health Plans: Are They More Than Talk Now?” Health Affairs, Web exclusive. Available at http:// content.healthaffairs.org/cgi/reprint/hlthaff.w2.395v1.pdf.

Goldfarb, N., V. Maio, C. Carter, L. Pizzi, and D. Nash. 2003. How Does Quality Enter into Health Care Purchasing Decisions? New York: The Commonwealth Fund. Available at http://www.cmwf.org/programs/quality/goldfarb_ healthcarepurchasing_ib_635.pdf

Grossbart, S. 2003. "The Business Case for Safety and Quality: What Can Our Databases Tell Us?" Presented at the 5th Annual NPSF Patient Safety Congress, March 15, Washington, DC.

Ho, S. 2004. "Medicare: Paying for Performance." Presented at the John F. Kennedy School of Government/The Commonwealth Fund Bipartisan Congressional Health Policy Conference, January, Florida.

Huskamp, H. A., P. A. Deverka, A. M. Epstein, R. S. Epstein, K. A. McGuigan, and R. G. Frank. 2003. "The Effect of Incentive-Based Formularies on Prescription Drug Utilization and Spending." New England Journal of Medicine 349 (23): 2224-32.

Institute for Healthcare Improvement. 2003. Move Your Dot. Boston, MA: Institute for Healthcare Improvement.

Lohr, K. N. 1986. "Use of Medical Care in the RAND HIE." Medical Care 24 (9, supplement): S1-87.

Lo Sasso, A. T., T. Rice, J. R. Gabel, and H. Whitmore. 2004. "Tales from the New Frontier: Pioneers' Experiences with Consumer-Driven Health Care.” Health Services Research 39 (4, part 2): 1071-90.

Lurie, N., W. G. Manning, C. Peterson, G. A. Goldberg, C. A. Phelps, and L. Lillard. 1987. "Preventive Care: Do We Practice What We Preach?" American Journal of Public Health 77 (7): 801-4.

Lurie, N., N. B. Ward, M. F. Shapiro, and R. H. Brook. 1984. "Termination from Medi-Cal: Does It Affect Health?” New England Journal of Medicine 311 (7): 480-4.

Maio, M., N. Goldfarb, C. Carter, and D. Nash. 2003. Value-Based Purchasing: A Review of the Literature. New York: The Commonwealth Fund. Available at http:// www.cmwf.org/programs/quality/maio_valuebased_636.pdf. 
McGlynn, E. A., S. M. Asch, J. Adams, J. Keesey, J. Hicks, A. DeCristofaro, and E. A. Kerr. 2003. "The Quality of Health Care Delivered to Adults in the United States." New England Journal of Medicine 348 (26): 2635-45.

McNeill, D. 2004. "Do Consumer-Directed Health Benefits Favor the Young and Healthy?" Health Affairs 23 (1): 186-93.

Milstein, A. 2003. "Restorers, Skin-grafters and Calibrators: A Five-Year Forecast for Large Employer Cost Sharing." Presented at Health System Change Patient Cost Sharing Conference, December 3, Washington, DC.

Monheit, A. C. 2003. "Persistence in Health Expenditures in the Short Run: Prevalence and Consequences." Medical Care 41 (7, supplement): III53-64.

Newhouse, J. P. 1981. "Some Interim Results from a Controlled Trial of Cost Sharing in Health Insurance." New England Journal of Medicine 305 (25): 1501-7.

Parente, S. T., R. Feldman, and J. B. Christianson. 2004a. "Employee Choice of Consumer-Driven Health Insurance in a Multiplan, Multiproduct Setting." Health Services Research 39 (4, part 2): 1091-112.

2004b. "Evaluation of the Effect of a Consumer-Driven Health Plan on Medical Care Expenditures and Utilization." Health Services Research 39 (4, part 2): 1189210.

Rasell, M. E. 1995. "Cost Sharing in Health Insurance: A Reexamination." New England Journal of Medicine 332 (17): 1164-8.

Rosenthal, M., and A. Milstein. 2004. "Awakening Consumer Stewardship of Health Benefits: Prevalence and Differentiation of New Health Plan Models." Health Services Research 39 (4, part 2): 1055-70.

Schoenbaum, S. C., A. J. Audet, and K. Davis. 2003. "Obtaining Greater Value from Health Care: The Roles of the U.S. Government." Health Affairs 22 (6): 183-90.

Siu, A. L., F. A. Sonnenberg, W. G. Manning, G. A. Goldberg, E. S. Bloomfield, J. P. Newhouse, and R. H. Brook. 1986. "Inappropriate Use of Hospitals in a Randomized Trial of Health Insurance Plans." New England Journal of Medicine 315 (20): 1259-66.

Soumerai, S. B., J. Avorn, D. Ross-Degnan, and S. Gortmaker. 1987. "Payment Restrictions for Prescription Drugs Under Medicaid. Effects on Therapy, Cost, and Equity." New England Journal of Medicine 317 (9): 550-6.

Soumerai, S. B., T. J. McLaughlin, D. Ross-Degnan, C. S. Casteris, and P. Bollini. 1994. "Effects of Limiting Medicaid Drug-Reimbursement Benefits on the Use of Psychotropic Agents and Acute Mental Health Services by Patients with Schizophrenia." New England Journal of Medicine 331 (10): 650-5.

Soumerai, S. B., D. Ross-Degnan, J. Avorn, T. McLaughlin, and I. Choodnovskiy. 1991. "Effects of Medicaid Drug-Payment Limits on Admission to Hospitals and Nursing Homes." New England Journal of Medicine 325 (15): 1072-7.

Stuart, B., and C. Zacker. 1999. "Who Bears the Burden of Medicaid Drug Copayment Policies?” Health Affairs 18 (2): 201-12.

Tamblyn, R., R. Laprise, J. A. Hanley, M. Abrahamowicz, S. Scott, N. Mayo, J. Hurley, R. Grad, E. Latimer, R. Perreault, P. McLeod, A. Huang, P. Larochelle, and L. Mallet. 2001. "Adverse Events Associated with Prescription Drug Cost-Sharing 
among Poor and Elderly Person.” Journal of the American Medical Association 285 (4): 421-9.

Tollen, L., M. Ross, and S. Poor. 2004. "Risk Segmentation Related to the Offering of a Consumer-Directed Health Plan: A Case Study of Humana Inc." Health Services Research 39 (4, part 2): 1167-88.

Wong, M. D., R. Andersen, C. D. Sherbourne, R. D. Hays, and M. F. Shapiro. 2001. "Effects of Cost Sharing on Care Seeking and Health Status: Results from the Medical Outcomes Study." American Journal of Public Health 91 (11): 1889-94. 
1234 